\title{
Educação para as sexualidades: sentindo e movimentando o próprio corpo para novas descobertas e possibilidades de ação docente
}

\author{
Carolina Faria Alvarenga \\ Universidade Federal de Lavras \\ Vanderlei Barbosa \\ Universidade Federal de Lavras
}

\section{Resumo}

Este trabalho foi elaborado a partir de reflexões de educadoras da Educação Infantil que participaram de um curso de extensão sobre psicomotricidade relacional. O jogo e a relação corporal foram elementos centrais nesse processo de formação. Por meio de elementos da terapia psicomotora, como brincadeiras - livres e orientadas - com bolas de variados tamanhos, jornais e papeis picados, foi possibilitado às educadoras experimentarem o prazer do corpo e o prazer por meio do movimento do próprio corpo. Ter consciência de seu corpo, de seus contornos e de seu potencial foi um dos maiores desafios apresentados pelas educadoras. Foram, então, instigadas a pensar, diante da dificuldade em lidarem com o próprio corpo, sobre como o trabalho a partir da perspectiva da educação para as sexualidades estaria sendo realizado com crianças da Educação Infantil. Os relatos apontam que, atualmente, as propostas de educação, cada vez menos, priorizam o corpo, o toque, o contato corporal, as sensações, por meio de brincadeiras, a favor de um processo acelerado de alfabetização. Dessa forma, cursos de formação continuada docente que possibilitem repensar as ações pedagógicas que se realizam com as crianças tornam-se cada vez mais importantes.

Palavras-chave: Educação Infantil, Educação continuada docente, Educação para as sexualidades. 


\title{
Education sexualities: feeling and moving the body to new discoveries and possibilities of teacher action
}

\begin{abstract}
This work was made from reflections of the kindergarten teachers who participated in an extension course on relational psychomotricity. The game and the relationship body were central elements in this training process. Through elements of psychomotor therapy, as jokes - free and targeted - with balls of various sizes, shredded newspapers and papers, was allowed teachers to experience the pleasure and the pleasure of the body through movement of the body itself. Be aware of your body, its contours and its potential was one of the biggest challenges presented by teachers. Were then enticed to think, given the difficulty in dealing with their own bodies, about the work from the perspective of education for sexuality was being conducted with children from kindergarten. There are reports that, currently, proposals for education, fewer, prioritize your body, the touch, the contact body, sensations, through play, in favor of an accelerated literacy. Thus, teaching continuing education courses that enable rethink pedagogical actions with the kids become increasingly important.
\end{abstract}

Keywords: Kindergarten, teaching continuing education, Education sexualities. 
Este trabalho ${ }^{1}$ é fruto de nossa experiência vivenciada no curso de extensão "Psicomotricidade relacional na Educação Infantil: curso teórico e prático", realizado pelo Departamento de Educação da Universidade Federal de Lavras - UFLA, no período de 5 a 9 de novembro de 2012 e ministrado pelo educador italiano Carlo Zilio ${ }^{2}$. O curso foi destinado a educadoras ${ }^{3}$ de Educação Infantil no município de Lavras e região ${ }^{4}$

O objetivo de nossa reflexão é recuperar os principais aspectos desenvolvidos no curso, na tentativa de articular as relações entre a(s) infância(s), o brincar, a educação para as sexualidades e a formação continuada docente.

Apontamos três grandes vertentes que irão guiar nossa reflexão. A primeira refere-se ao conceito de infância(s). A segunda vertente centra-se nos preceitos teórico-metodológicos da psicomotricidade trabalhados ao longo do curso, ou seja, os jogos e as brincadeiras como eventos constituidores do universo infantil e propulsores do desenvolvimento estético e ético, tendo o prazer do corpo como mediação. E, por fim, as possibilidades de se pensar a formação continuada docente na perspectiva de uma educação para as sexualidades no contexto da Educação Infantil, a partir da articulação entre as duas primeiras vertentes. Seguindo, intencionalmente, o propósito do curso, esse texto pretende equilibrar a teoria e a prática: esse contrabalançar é importante porque a teoria sem a destinação prática é delírio e a prática destituída de teoria é ativismo vazio. Portanto, o nosso desejo é que a teoria esteja recheada de intencionalidade prática e a prática impregnada de solidez teórica.

$1^{\urcorner}$Trabalho apresentado no Seminário Internacional Fazendo Gênero 10: Desafios atuais dos Feminismos e publicado nos anais eletrônicos do evento. Disponível em: http://www.fazendogenero.ufsc.br/10/site/anaiscomplementares.

$2\urcorner \mathrm{O}$ educador Carlo Zilio, do Instituto Italiano de Psicologia della Relazione, em Zelarino (Veneza), é licenciado em Literatura Moderna pela Faculdade de Letras da Universidade de Pádua/ Itália e pós-graduado em Psicomotricidade Relacional, tendo como mentores Mauro Vecchiato e Marta Gonzalez Menéndez.

$3^{\urcorner}$Havia apenas um educador.

47 Estiveram presentes educadoras e educadores que participam do Fórum Sul Mineiro de Educação Infantil.

Olh@res, Guarulhos, v. 2, n.2, p. 335-351. Dezembro, 2014. 
Educação para as sexualidades: sentindo e movimentando o próprio corpo para novas descobertas e possibilidades de ação docente

Infâncias, corpos e sexualidades: desafios às e aos profissionais da Educação Infantil

A noção de infância, atualmente, é parte constante do debate e dos questionamentos das políticas públicas, mas, historicamente, não foi sempre assim. Embora seja salutar colocar em evidência a discussão sobre a(s) infância(s), não se pode deixar de lutar, permanentemente, pela efetiva conquista e materialização dos seus direitos.

A infância é uma categoria sócio-histórica em permanente reconstrução, negociação, envolvida por relações de poder. Ao longo da história da humanidade, a criança foi, segundo Ana Maria Faccioli de Camargo e Cláudia Ribeiro (1999), tratada de diferentes formas. Muitos foram (e ainda são) os discursos, as práticas e as ideias sobre a criança. Sob uma perspectiva adulta, a criança, tida como objeto de estudo, tem desconsideradas suas especificidades. As formas como são tratadas e educadas refletem as concepções vigentes em cada época da história da humanidade.

Do discurso religioso passa-se para a centralidade dos conhecimentos científicos. Com o advento da ciência moderna, no século XIX, em que novas áreas do conhecimento se destacam, como a biologia e as ciências humanas, a infância continua a ser controlada, vigiada, estudada e as crianças tratadas como terceira pessoa no discurso dos adultos. Nesse contexto, concepções e imagens sobre a infância circulam a partir da Psicologia, da Biologia, da Psicanálise e da Pedagogia (CAMARGO e RIBEIRO, 1999).

Nesse contexto, as "verdades" produzidas sobre a infância culminaram com a implementação de políticas higienistas, trazendo muitas mudanças na organização das famílias e nas instituições escolares. Preocupadas com possíveis desajustes e patologias sociais, em especial, das crianças, consideradas como o futuro da humanidade, as práticas médicas tornaram-se centrais na relação com as famílias e as escolas. A partir do controle e da repressão, em especial, da 
sexualidade, a ética burguesa "infiltrava-se na educação da criança travestida na forma de educação física, intelectual e moral" (CAMARGO e RIBEIRO, 1999, p. 23).

Como consequência, segundo as autoras, os espaços familiar e escolar se transformaram em ambientes de formação das crianças e adolescentes por meio de uma educação dos corpos e do sexo, que passava pelo "não-dito, pelo falar o mínimo possível e pelo controle do que era falado, de quem falava e onde se falava" (CAMARGO e RIBEIRO, 1999, p. 24).

Partimos do entendimento de que, em meio a um contexto de dominação e disciplinarização dos corpos, há também a produção de resistência (FOUCAULT, 1977). Nós, adultos/as, resistimos, e as crianças - meninas e meninos - também resistem. Porém, a ideia de um devir-criança e não um vir-a-ser criança, já determinado antes de ser (KATZ, 1996 apud CAMARGO e RIBEIRO, 1999), nos desestabiliza, nos incomoda, retira muitas de nossas referências, em especial, no trabalho como educadoras e educadores.

Portanto, questionamo-nos: se ainda hoje a sexualidade é tratada como tabu, apesar de muitas mudanças culturais, sociais, políticas e econômicas, que refletem em nossas práticas educativas, como educadoras (e educadores, quando há) de Educação Infantil lidam com seus corpos, desejos, descobertas, medos e inquietações? Pelas experiências que tiveram em sua infância, somando-se às que atravessaram suas vidas até a idade adulta, sentem-se seguras/os, confortáveis e preparadas/os para lidar com o inesperado, os impossíveis e os imprevisíveis que as crianças as/os apresentam (LARROSA, 1999)?

Pesquisas afirmam que ainda são incipientes as discussões sobre sexualidades (e gênero) nos currículos de formação docente (ECOS, 2008; VIANNA e UNBEHAUM, 2006). Dessa forma, para além desse desafio, ainda longe de ser conquistado, afirmamos que o trabalho intencionalmente planejado e realizado em torno dessas temáticas, para além dessa necessidade de formação inicial e continuada, precisa estar articulado a práticas que valorizem, no Olh@res, Guarulhos, v. 2, n. 2, p. 335-351. Dezembro, 2014. 
universo infantil, a corporeidade, o movimento, a brincadeira, a liberdade de expressão, mas também uma vivência do próprio corpo, adulto, que educa, fala, sente, aconchega e transforma.

Essa é, portanto, nossa concepção de educação para as sexualidades. É compreender que, ao se pensar nessa perspectiva, relacionam-se os conceitos de gênero, identidades sexuais, movimentos feministas e homossexuais, história do corpo e da sexualidade, violência sexual, entre outros (XAVIER FILHA, 2009). A partir do referencial de Michel Foucault (1988), entendemos a sexualidade como um discurso, permeado por relações de poder-saberverdade. Considerando que as questões de gênero estão relacionadas às de sexualidade (LOURO, 1997), podemos também afirmar que o que envolve as masculinidades e as feminilidades, o ser homem e o ser mulher, em nossa sociedade, também estão imbricados pelas relações de poder-saber-verdade.

A partir desses pressupostos, apresentamos, sucintamente, como aconteceu o curso de extensão "Psicomotricidade relacional na Educação Infantil: curso teórico e prático" e quais os pressupostos teóricos que o embasam, para, então, tentarmos pensar as possibilidades de um trabalho docente que envolva a educação para as sexualidades.

Buscamos, inicialmente, compreender o processo de disciplinarização do corpo (FOUCAULT, 1977; 1988), mas também sobre o desenvolvimento de outras possibilidades humanas da criança, pois não podemos subjugá-la apenas aos interesses do mundo produtivo, mas partindo do princípio que o jogo e o brincar infantil podem minimizar os efeitos dessa excessiva disciplinarização, uma vez que, para além do desenvolvimento das habilidades sensitiva, perceptiva, cognitiva, motora e sócio-afetiva, podemos observar, no jogo e no brincar, outros elementos de exploração, de criatividade e de prazer. No jogo e na brincadeira, a criança fantasia, sonha, aceita desafios e se desenvolve. Portanto, a cultura lúdica infantil exige pluralidade, intersubjetividade, movimento e, a partir de suas raízes, como ser histórico, a criança inicia a construção de sua identidade. Olh@res, Guarulhos, v. 2, n. 2, p. 335-351. Dezembro, 2014. 
Destacamos, porém, que o arcabouço teórico apresentado por Carlo Zilio, educador responsável pelo curso, baseia-se fundamentalmente na Psicanálise e alguns conceitos trabalhados vão de encontro ao referencial utilizado por nós nesse trabalho, especialmente quando se relaciona o processo da psicomotricidade ao tratamento de patologias. Contudo, apesar de algumas divergências teóricas, consideramos que, durante o curso, as discussões possibilitam construirmos um momento único de formação docente.

O corpo, o brincar e a alegria: preceitos teórico-metodológicos da psicomotricidade relacional

Segundo Carlo Zilio (2012), a estrutura e o funcionamento da vida psíquica, isto é, as bases da personalidade de cada indivíduo, se constituem nos primeiros anos de vida e isso ocorre, de modo particular, por meio da experiência que a criança faz pelo seu corpo e graças ao movimento que desenvolve.

É importante salientar que a vida psíquica é um todo complexo que se retroalimenta o tempo todo, ou seja, os processos primários continuam a agir nos processos secundários e vice-versa na busca incessante do equilíbrio psíquico. Portanto, corpo e mente, "ser" e "não ser", dentro e fora, antes e depois são ecos de uma mesma complexidade que nos constitui.

Zilio (2012) faz distinção sobre o desenvolvimento ontogenético do indivíduo, entre normalidade e patologia. A partir de uma concepção freudiana, o educador afirma que "o núcleo inicial da psique é idêntico em todos os seres humanos. Temos todos os mesmos impulsos, cuja origem é genética; os mesmos fantasmas originários de fusões e difusões que alimentam a dinâmica da personalidade" (ZILIO, 2012, p. 3). Na fase inicial, a criança vive centrada em si mesma e é o que chama de uma "normal fase psicótica", da qual sairá progressivamente, construindo a própria individualidade pelo processo de individuação. Para Zilio (2012, p. 3), 
consciência (primeiros meses) de ser alguém; sucessivamente, mesmo desenvolvendo essa consciência do ser, é prisioneira do seu narcisismo, da necessidade quase imediata de atender as necessidades (princípios de prazer), o que o leva a desenvolver uma comunicação em sentido único onde ela é o centro do mundo (identidade de percepção). Os mesmos impulsos motivacionais que derivam dos fantasmas arcaicos de fusão e difusão levam a criança a procurar continuamente situações regressivas de intimidade onde se encontrar e se recarregar, como também situações de afirmação e movimento onde experimentar as próprias potencialidades e aumentar a consciência de si, criando um "estado normal de neurose" ao não saber qual das duas instâncias satisfazer primeiro e/ou por mais tempo, no temer de perder as primeiras enquanto satisfaz as segundas e vice versa.

A psicomotricidade surge aqui como uma experiência capaz de favorecer a superação da dicotomia mente e corpo (passagem do eu corporal para o eu mental). Sendo assim, determina o amadurecimento positivo do indivíduo (percepção de pensamento) que viverá de modo mais integrado (princípio de realidade).

Porém, é necessário ressaltar que a psicomotricidade, nesse texto, tem como objetivo a dinâmica, o movimento e o jogo do ponto de vista pedagógico e não propriamente psicológico. A educação é, para nós, um fenômeno humano e social, com suas determinações históricas. Educar é produzir o ser humano, construir sua identidade ontológica, social, cultural, étnica.

Nessa perspectiva, caberá aos/às educadores/as aprender a usar das diversas possibilidades da psicomotricidade para potencializar o desenvolvimento e a maturidade das crianças por meio dos jogos e das brincadeiras, facilitando o processo de individuação. Essa apropriação pedagógica da psicomotricidade pode ser feita utilizando as mesmas etapas ou tipologias da terapia psicomotora, a saber: jogo sensóriomotor, jogo simbólico, jogo de socialização. Explicitemos sucintamente cada uma delas, de acordo com o educador (ZILIO, 2012):

Jogo sensório-motor: é a experiência por meio da qual a criança estrutura de modo preciso a consciência de seu corpo, de seus contornos e de seu potencial. O importante no jogo sensório-motor é propor situações que permitam a criança experimentar o prazer do corpo, o prazer por meio do movimento (15 minutos).

Jogo simbólico: é a experiência do "como se", que envolve as instâncias psicológicas, as fantasias, os fantasmas, os medos e Olh@res, Guarulhos, v. 2, n. 2, p. 335-351. Dezembro, 2014. 
conflitos, bem como as memórias afetivas vividas com alegria, emoção e gratuidade. Nessa dinâmica, a criança vivencia um processo de regressão e desenvolve aquilo que na psicanálise se chama de transferência que pode ser positiva (amor) ou negativa (ódio) (30 minutos).

Jogo de socialização: é a experiência de socializar suas emoções, o que significa sair de uma posição egocêntrica para uma posição de autonomia, o que demonstra um processo de amadurecimento e uma importante estruturação da vida psíquica (15 minutos).

Essa dinâmica, alternando entre os jogos sensório-motor, simbólico e de socialização, favorece as etapas do processo de maturidade da criança que é adquirir consciência do corpo, fazer a regressão das experiências afetivas e conquistar, via progressão, a autonomia. Porém, o sucesso desse jogo depende da capacidade do/a educador/a ser constantemente atento/a à criança e saber fazer a leitura de seus movimentos corporais (o corpo também fala) e dos seus sinais (verbal, não verbal, euforia, introspecção, alegria, tristeza). Para isso, torna-se necessário desenvolver uma "relação de empatia" com a criança, lembrando sempre que, nessa relação, não é a mente que nos guia, mas sim o nosso coração (ZILIO, 2012, p. 15). Sem a conquista da confiança, o diálogo não será operativo e não trará resultados benéficos. Há que se lembrar do poeta de Três Pontas: "há que se cuidar do broto para que a vida nos dê fruto e flor".

Os materiais utilizados na dinâmica são objetos simples que têm como finalidade favorecer o desenvolvimento das três tipologias de jogo psicomotor. Os materiais mais frequentes são: bolas, bambolês, corda, papel, tecidos, caixas de papelão, colchonetes, tubos de papelão, blocos lúdicos, instrumentos musicais, tinta, comida, música, linguagem verbal e mímica. Diante desse arsenal de objetos, o importante é criar uma relação de empatia, confiança e diálogo que deixem todas as crianças à vontade e motivadas para a experiência.

A partir das discussões decorrentes das leituras e vivências durante o curso, compreendemos que a terapia psicomotora prioriza as Olh@res, Guarulhos, v. 2, n. 2, p. 335-351. Dezembro, 2014. 
Educação para as sexualidades: sentindo e movimentando o próprio corpo para novas descobertas e possibilidades de ação docente

experiências com o corpo, em uma relação eu-outro, por meio de objetos intencionalmente planejados. O trabalho pode ser realizado em clínicas, com fins terapêuticos, individualmente ou em grupos, mas também em instituições educativas, visando outras experiências pelas crianças. Nesse contexto, é o/a terapeuta quem realiza o trabalho, conduz, avalia, (re)planeja.

Porém, nosso desafio, nesse artigo, é articular os princípios teórico-metodológicos da psicomotricidade relacional à formação e à prática docentes, a partir de uma concepção múltipla de infância, que inclui o brincar e a educação para as sexualidades (e gênero) como elementos inseparáveis.

Educação para as sexualidades na Educação Infantil a partir da vivência do próprio corpo

"A partir do momento em que eu estava aberta para receber (deitada), as pessoas vieram."

(Depoimento de uma educadora durante o curso)

Ao retomarmos o argumento de que o entendimento sobre a infância está em constante processo de mudanças e negociações, ancoramo-nos na Sociologia da Infância para afirmar que há muitas infâncias e as crianças são produtoras de cultura, são ativas, interagem, questionam, resistem, silenciam. Segundo Sônia Kramer (2007, p. 15), “crianças são sujeitos sociais e históricos, marcadas, portanto, pelas contradições das sociedades em que estão inseridas”.

Relacionando com as temáticas de gênero e sexualidade, no cotidiano da Educação Infantil, não é possível escapar do trabalho com temas tão delicados. Constantina Xavier Filha (2012) entende que

\footnotetext{
mesmo sem a pretensão de realizar algo sistematizado a respeito, a educação ocorre nas relações cotidianas entre adultos e crianças, nas inúmeras expressões de sexualidade destas, nas normas e regras impostas nodisciplinamento e docilização dos corpos, nas separações entre meninos e meninas. O tempo todo estamos interagindo e educando com pedagogias de sexualidade e gênero, que prescrevem o que deve ser feito para atingir o ideal de feminilidade e masculinidade, o que socialmente se convencionou chamar de sexualidade "normal", entre outros conceitos (XAVIER FILHA, 2012, p. 278).
}

Olh@res, Guarulhos, v. 2, n. 2, p. 335-351. Dezembro, 2014. 
Portanto, a todo o momento, várias são as "situações, perguntas, ações, brincadeiras e conflitos” (p. 277) que acontecem na Educação Infantil e são muitas as formas para se trabalhar intencionalmente a partir da perspectiva da educação para as sexualidades, que também inclui as questões de gênero.

Independente do termo que se usa - "educação para as sexualidades", "educação em sexualidade", "educação sexualizada", "educação afetivo-sexual" - o mais importante é a reconstrução dos discursos que o embasa e a concepção que ultrapassa o aspecto biologizante. Xavier Filha (2009) utiliza-se do termo "educação para as sexualidades", pois possibilita a relação com outras dimensões que envolvem nossa identidade.

Nesse contexto, consideramos os brinquedos, os jogos e as brincadeiras como ricas possibilidades para o desenvolvimento do trabalho nessa perspectiva apresentada. É preciso, então, nos questionar: de que maneira podemos assegurar nas nossas práticas educativas que o brincar seja vivido como experiência de cultura? Colocando à disposição das crianças materiais e objetos para descobertas, ressignificações, resistências? Ângela Borba responde:

Compartilhando brincadeiras com as crianças, sendo
cúmplices, parceiras, apoiando-as, respeitando-as e
contribuindo para ampliar seu repertório. Observando-as
para melhor conhecê-las, compreendendo seus
universos e referências culturais, seus modos próprios
de sentir, pensar e agir, suas formas de se relacionar
com os outros (BORBA, 2007, p. 44).

O próprio corpo também traz muitas possibilidades para essas vivências e exploração da infância como produto e produtora de cultura. A autora complementa que, nesse sentido, assim como a brincadeira, o jogo deve

ser livre, espontâneo, não ter hora marcada, nem resultados prévios e determinados. Isso não significa que não possamos utilizar a ludicidade na aprendizagem, mediante jogos e situações lúdicas que propiciem a reflexão sobre conceitos matemáticos, linguísticos ou científicos. Podemos e devemos, mas é preciso colocá-la no real espaço que ocupa no mundo infantil, e que não é o da experiência da brincadeira como cultura (BORBA, 2007, p. 43). 
Educação para as sexualidades: sentindo e movimentando o próprio corpo para novas descobertas e possibilidades de ação docente

Essa compressão, que também foi cenário de discussão durante o curso, está presente nas avaliações das educadoras e dos educadores. Além disso, suas reflexões mostram que, além da importância do brincar, é possível fazê-lo com objetos simples, presentes nas instituições de Educação Infantil, ou até mesmo com o próprio corpo:

O curso em si foi ótimo, os materiais diversos nos proporcionaram momentos de novas descobertas, inclusive interior, onde sensações e curiosidades foram vividas intensamente (Educadora A.).

Gostei de sentir a liberdade de poder brincar, já que não tiramos um tempo para relaxar e brincar. Adorei ter contato com outras pessoas. Percebi que por mais que nos sentimos sozinhos às vezes, sempre há alguém para nos acolher (Educadora B.).

Descobrir as diversas possibilidades de sentir prazer, alegria, interações, interiorização, descobertas estas que podemos alcançar utilizando materiais do nosso cotidiano. Um novo olhar sobre a psicomotricidade surgiu. Todos os momentos vivenciados fizeram com que eu me sentisse melhor como pessoa e profissional. $O$ material teórico disponibilizado foi muito significativo e nos faz refletir nossa prática e provoca mudanças (Educadora C.).

Como o curso permitiu que experimentássemos nosso próprio corpo, objetos (bolas, tecidos, jornal), músicas e muitas sensações, os relatos, após cada vivência, refletem essas diversas possibilidades de sentir prazer, alegria, interações, interiorização, destacada anteriormente por uma das educadoras:

Nossa, uma hora brincando de bola? Não paramos de brincar por um minuto! Damos esse tempo para as crianças? (Educadora D.).

Nós, adultos, sentimos falta de atividades lúdicas; dificuldades de toque, cantar baixinho, conversar sozinha. (Educadora E.)

Arrepiava de medo de ter que me expor! A música e relaxamento foram muito bons (Educadora F.).

Conseguimos ficar em silêncio. Não fiquei com medo de ficar por baixo, pois senti o acolhimento, o cuidado; importância de cuidar do outro. (Educadora G.) $O$ que as crianças sentiriam ali? Qual seria a atitude das crianças? Só pensei nas crianças e relaxei apenas quando fui tocada! (Educadora H.)

Algo que marcou muito a fala das e dos educadoras pode ser resumido em: "O toque, a dança, a música foi uma experiência única” (Educadora I.). Porém, também durante nossas conversas, questionamos a partir do que Borba (2007, p. 35) apresenta: "É possível organizar nosso trabalho e a instituição educativa de outra forma, de modo que o espaço para a fruição, para o fazer estético e para a brincadeira seja garantido?”. Essa discussão foi decorrente da preocupação sobre uma valorização cada vez mais crescente em 
relação à alfabetização, desconsiderando o brincar, a corporeidade, o lúdico, em especial, com as crianças de quatro e cinco anos:

\begin{abstract}
Proponho uma continuidade em momentos possíveis. E a partir desta experiência, proporcionarei em nossa escola não uma terapia, mas sim propor a elas possibilidades do toque, o cooperar, a alegria, a música, enfim ser feliz! (Educadora I.)

Gostaria de aprofundar mais, pois o conhecimento do corpo e do outro é fundamental em nossa prática. Precisamos de mais subsídios para intervir no processo de desenvolvimento das crianças. (Educadora A.)
\end{abstract}

Além do desafio, na perspectiva de um trabalho que envolva a educação para as sexualidades, acrescentamos: temos permitido, em nossa prática com as crianças, que meninas e meninos vivenciem seus corpos, o movimento, o toque, o prazer, as descobertas de forma lúdica, como um verdadeiro momento de experiência, nos termos de Jorge Larrosa (2002)? Em uma das avaliações, uma educadora sugere:

\begin{abstract}
Formação e estudo: curso de sexualidade para "Educação Infantil”" proporcionando participação de educadoras regentes na educação infantil. Já participei de vários, porém penso que as escolas ainda não estão preparadas para estas situações. Minhas colegas têm medo de trabalhar este tema. (Educadora C.).
\end{abstract}

Apesar da preocupação com a temática e por afirmar que já participou de vários cursos, destacamos de sua fala ainda uma concepção de que trabalhar na perspectiva de uma educação para as sexualidades é apenas lidar com "situações". Também o é, quando crianças nos fazem perguntas, são vítimas de violências sexuais ou outras situações que "nos deixam de cabelo em pé" (CASTANHEIRA E ALVARENGA, 2012). Porém, Carlo Zilio, ao falar, durante nossas vivências no curso, sobre a "liberdade da psicomotricidade em criar contato" nos ajuda a pensar para além das "situações". E, por isso, o trabalho com nosso próprio eu, nosso corpo, nossa intimidade também é importante. Os relatos das educadoras anunciam isso:

\footnotetext{
As experiências vividas nesses dias foram de grande importância para mim. Vivenciei situações inéditas. Quem sou eu? Como me vejo? Como gostaria que mevissem? Como me sinto? Como me percebo no mundo? (Educadora D.)

O curso foi completamente diferente de todos que já fiz em minha vida. Percebemos que primeiro devemos vivenciar e analisarmos a nós mesmos, para depois
}

Olh@res, Guarulhos, v. 2, n. 2, p. 335-351. Dezembro, 2014. 
Educação para as sexualidades: sentindo e movimentando o próprio corpo para novas descobertas e possibilidades de ação docente

podermos verificar, assim dizendo, o comportamento alheio. (Educadora F.)

Acredito que tudo funcionou bem. Consegui expressar sentimentos e fazer coisas que me fizeram viajar, refletir. Os materiais operacionais, a preparação dos momentos fizeram com que eu compartilhasse toque, que dançasse e me entregasse. Muito bom. Terapêutico. (Educadora C.)

Seria muito bom a retomada do tema psicomotricidade, objetivos, sentidos, vivência. Precisamos resgatar esses espaços nas creches, Educação Infantil de Lavras e a continuar a preparar os profissionais através da terapia para entenderem a importância desse meio para o desenvolvimento integral de nossas crianças. Gostaria de ser informada de mais cursos relacionados. (Educadora G.)

Momentos de interação com o outro, oportunidade de descobertas; tocar e ser tocado/a; acréscimo de conhecimento mais específico em relação à psicomotricidade relacional; discussões pertinentes ao momento histórico em que a sociedade se encontra. (Educador A.)

De forma geral, gostei de cada dia, porque tive oportunidades de encontrar esse contato comigo mais uma vez. (Educadora B.)

\section{Considerações finais}

Esse estudo teórico-prático foi elaborado tendo como perspectiva investigar as atividades lúdicas, como possibilidades de aprendizagem e desenvolvimento da criança entendida como sujeito de direitos. E o que pudemos inferir do curso foi a necessidade de criação de repensarmos nossas ações pedagógicas para criarmos vínculos entre as educadoras e os educadores no sentido de partilhar as limitações e as possibilidades no tratamento das questões da educação para as sexualidades, sentindo e movimentando o próprio corpo para novas descobertas e possibilidades de ação docente. Corrobora essa percepção o relato de uma das educadoras que, no momento da avaliação final do curso, destacou os pontos positivos:

Partilha (material, lanche, experiências, etc.); autoconhecimento; manifestações das emoções; material teórico, interação/integração; o corpo como possibilidade e não como limite; respeito a si mesmo e ao próximo; diversidade de cores, texturas, tamanhos, etc. dos materiais utilizados. (Educadora C.)

É importante lembrar que não é o fato da criança passar da Educação Infantil para o Ensino Fundamental que a brincadeira deve deixar de existir (ou mesmo antes, aos quatro anos, no início da préescola, quando essa preocupação toma maiores proporções). Uma educação, na sua concepção integral, deve priorizar em todas as etapas

Olh@res, Guarulhos, v. 2, n. 2, p. 335-351. Dezembro, 2014. 
da formação as atividades ligadas às artes e ao lúdico, tendo sempre o máximo de consciência possível de nosso corpo, pois todas as ações que tecem a trama da vida envolvem a mediação da corporeidade (LE BRETON, 2011).

Encerrando esse texto e tomando a corporeidade como referencial e modo de ser no mundo, recorremos às palavras do filósofo francês Merleau-Ponty (1992, p. 9), que diz: “O corpo é um visível que se vê, um tocado que se toca, um sentido que se sente. $\mathrm{O}$ corpo é um instrumento de percepção e consciência perceptiva é a consciência existencial". Que a forma como nos relacionamos com nossos corpos nos permita sermos mais livres, mais lúdicas e lúdicos e, portanto, mais humanas e humanos. 
Educação para as sexualidades: sentindo e movimentando o próprio corpo para novas descobertas e possibilidades de ação docente

\section{Referências}

BORBA, Ângela Meyer. O brincar como um modo de ser e estar no mundo. In: BEAUCHAMP, Jeanete; PAGEL, Sandra Denise; NASCIMENTO, Aricélia Ribeiro do (Orgs). Ensino fundamental de nove anos: orientações para a inclusão da criança de seis anos de idade. Brasília: Ministério da Educação, Secretaria de Educação Básica, 2007, p. 33-45.

CAMARGO, Ana Maria Faccioli e RIBEIRO, Cláudia Maria. Sexualidade(s) e infância(s): a sexualidade como um tema transversal. Campinas-SP: Ed. Moderna, 1999.

CASTANHEIRA, M. A. M.; ALVARENGA, Carolina Faria. Isso me deixa de cabelo em pé: depoimentos de educadoras de Educação Infantil sobre gênero e sexualidades. In: VI Congresso Internacional de Estudos sobre a Diversidade Sexual e de Gênero, 2012, Salvador. Anais do Congresso Internacional de Estudos sobre a Diversidade Sexual e de Gênero da ABEH, 2012. v. 1.

ECOS - Comunicação em sexualidade. As políticas de Educação em Sexualidade no Brasil - 2003 a 2008. Relatório Narrativo Anual. São Paulo: ECOS, 2008.

FOUCAULT, Michel. Vigiar e Punir. Petrópolis-RJ: Vozes, 1977.

História da Sexualidade I: a vontade de saber. Rio de Janeiro: Editora Graal, 167p., 1988.

KRAMER, Sônia. A infância e sua singularidade. In: BEAUCHAMP, Jeanete; PAGEL, Sandra Denise; NASCIMENTO, Aricélia Ribeiro do (Orgs). Ensino fundamental de nove anos: orientações para a inclusão da criança de seis anos de idade. Brasília: Ministério da Educação, Secretaria de Educação Básica, 2007, p. 13-23.

LARROSA, Jorge. Pedagogia profana: danças, piruetas e mascaradas. Tradução: Alfredo Veiga-Neto. Belo Horizonte: Autêntica, 1999.

Notas sobre a experiência e o saber de experiência. Revista Brasileira de Educação. Campinas, n.19, jan/abr, p. 20-29, 2002. 
LE BRETON, David. Antropologia do corpo e modernidade. Petrópolis-RJ: Vozes, 2011.

LOURO, Guacira Lopes. Gênero, sexualidade e educação: uma perspectiva pósestruturalista. Petrópolis: Vozes, 1997.

MERLEAU-PONTY, Maurice. O visível e o invisível. Trad. José Artur Giannotti e Armando Mora Oliveira. São Paulo: Editora Perspectiva, 1992.

VIANNA, Cláudia; UNBEHAUM, Sandra. Gênero na educação básica: quem se importa? Uma análise de documentos de políticas públicas no Brasil. Educação \& Sociedade, Campinas, v.28, n.95, maio-ago, 2006.

XAVIER FILHA, Constantina. Educação para a sexualidade: carregar água na peneira? RIBEIRO, Paula Regina Costa; SILVA, Méri Rosane Santos da; GOELLNER, Silvana Vilodre (orgs.). Corpo, gênero e sexualidade: composições e desafios para a formação docente. Rio Grande: FURG, 2009, p. 85-103.

- Educação para as sexualidades, para a igualdade de gênero e para as diferença/diversidades: possibilidades pedagógicas. In: XAVIER FILHA, Constantina (Org.). Sexualidades, gênero e diferenças na educação das infâncias. Campo Grande: Editora UFMS, 2012, p. 277-293.

ZILIO, Carlo. Introdução à terapia psicomotora. Material produzido para o Curso Psicomotricidade relacional na Educação Infantil. Departamento de Educação Universidade Federal de Lavras, 2012. 